\title{
EFEKTIVITAS PEMAKAIAN FILTER BERPORI DAN KARBON AKTIF SEBAGAI MEDIA FILTER DALAM MENURUNKAN POLUTAN AIR PDAM
}

\section{Effectiveness of Used Milling Filter And Activated Carbon as a Filter Media In Reduce Polutan PDAM Water}

\author{
Arief Muliawan ${ }^{1}$, Finta Amalinda ${ }^{2}$ \\ 1Teknik Elektro, Sekolah Tinggi Teknologi Bontang \\ ${ }^{2}$ Fakultas Kesehatan Masyarakat, Universitas Muhammadiyah Palu \\ Email: ariefstitek@gmail.com
}

\begin{abstract}
ABSTRAK
Air distribusi PDAM pada umumnya masih mengandung Fe (zat besi) dan Mn (Mangan). Adanya kandungan Fe dan Mn dalam air ditandai dengan adanya perubahan fisis warna air menjadi kecoklatan dan pengendapan setelah air ditampung atau diendapkan pada bak penampungan. Telah dilakukan penelitian tentang pemanfaatan filter berpori dan karbon aktif sebagai media penyaring air PDAM Kota Bontang. Filter yang digunakan ialah $0,5 \mu \mathrm{m}, 0,3 \mu \mathrm{m}$ dan karbon aktif. Pengujian dilakukan dengan penentuan kandungan air pada tiap filter dan menentukan massa endapan yang tersaring selama 7 hari Hasil yang diperoleh pada saat air langsung diambil dari PDAM diperoleh kandungan besi 1,606 mg/l, mangan 0,157 mg/l dengan kekeruhan $91 \mathrm{NTU}$. Dengan dialirkan air ini pada filter 0,5 mikron diperoleh penurunan tingkat kandungan besi $1,101 \mathrm{mg} / \mathrm{l}$, mangan $0,141 \mathrm{mg} / \mathrm{l}$ dengan kekeruhan 74 NTU. Ditambah lagi dengan penyaringan 0,3 mikron diperoleh penurunan tingkat kandungan besi $0,309 \mathrm{mg} / \mathrm{l}$, mangan $0,083 \mathrm{mg} / \mathrm{l}$ dengan kekeruhan 42,49 NTU. Pada filter terakhir dengan penggunaan karbon aktif diperoleh penurunan tingkat kandungan besi $0,066 \mathrm{mg} / \mathrm{l}$, mangan $0,069 \mathrm{mg} / \mathrm{l}$ dengan kekeruhan 2,07 NTU. Pada hari ke 4 diperoleh perubahan massa filter 0,5 mikron sejumlah 25 gr dan filter 0,3 mikron sejumlah 4 gr. Sedangkan pada hari ke 7 diperoleh perubahan massa timbangan filter 0,5 mikron sejumlah 53 gr dan filter 0,3 mikron sejumlah 8 gr. Sedangkan pada karbon aktif tidak terjadi perubahan massa selama proses penfilteran. Dari hasil ini menunjukan bahwa penggunaan filter berpori 0,5 mikron, 0,3 mikron dan karbon aktif sangat baik untuk aliran air PDAM yang kurang bersih.
\end{abstract}

Kata Kunci ：Filter berpori, karbon aktif, air PDAM

\begin{abstract}
PDAM water distribution generally still contains $\mathrm{Fe}$ (iron) and Mn (Manganese). The presence of Fe and Mn content in water is characterized by a physical change of water color to brownish and sedimentation after the water is accommodated or deposited in a reservoir. A study has been conducted on the use of porous filters and activated carbon as a water filter media of Bontang City PDAM. The filters used are 0.5 $\mu \mathrm{m}, 0.3 \mu \mathrm{m}$ and activated carbon. The test was conducted by determining the water content of each filter and determining the mass of filtered sediment for 7 days. Results obtained at the time of water directly taken from PDAM obtained iron content $1.606 \mathrm{mg} / \mathrm{l}$, manganese $0.157 \mathrm{mg} / \mathrm{l}$ with turbidity $91 \mathrm{NTU}$. With this flowing water at a 0.5 micron filter obtained a decrease in iron content levels of $1.101 \mathrm{mg} / \mathrm{l}$, manganese $0.141 \mathrm{mg} / \mathrm{l}$ with turbidity $74 \mathrm{NTU}$. Coupled with 0.3 micron filtration obtained a decrease in the level of iron content of $0.309 \mathrm{mg} / \mathrm{l}$, manganese $0.083 \mathrm{mg} / \mathrm{l}$ with turbidity $42.49 \mathrm{NTU}$. In the last filter with the use of activated carbon, the iron content level decreased $0.066 \mathrm{mg} / \mathrm{l}, 0.069 \mathrm{mg} / \mathrm{l}$ manganese with turbidity $2.07 \mathrm{NTU}$. On the 4th day, there was a change of 0.5 micron filter mass of $25 \mathrm{~g}$ and 0.3 micron filter of $4 \mathrm{~g}$. While on day 7 obtained a change of mass of 0.5 micron filter scale of 53 grams and 0.3 micron filter of $8 \mathrm{gr}$. While on the activated carbon does not change the mass during the filtering process. From this result shows that the use of 0.5 micron, 0.3 micron and activated carbon filter is very good for water flow PDAM less clean.
\end{abstract}

Keywords $\quad$ : Porous Filters, Activated Carbon, PDAM Water

Sekretariat

Editorial: Kampus FKM UNISMUH PALU - Palu 94118, Sulawesi Tengah, Indonesia

Telp/HP: +6281245936241, Fax (0451) 425627

E-mail: jurnal.mppki@gmail.com

OJS: http://jurnal.unismuhpalu.ac.id/index.php/PJKM

\section{Article History:}

$\Rightarrow \quad$ Received 7 April 2018

$\Rightarrow \quad$ Revised 20 April 2018

$\Rightarrow \quad$ Accepted 16 Mei 2018

$\Rightarrow \quad$ Available online 25 Juni 2018 


\section{PENDAHULUAN}

Kota Bontang telah membangun unit pengelola air bersih dengan memanfaatkan air bawah tanah. Pengolahan air bersih berupa Water Treatment Process (WTP) yang berada di bawah pengawasan oleh PDAM Tirta Taman Kota Bontang. PDAM Kota Bontang melayani kebutuhan air bersih untuk masyarakat berbagai golongan. Dengan semakin bertambahnya jumlah penduduk di Kota ini maka semakin banyak kebutuhan akan air bersih. Suatu sistem penyediaan air yang mampu menyediakan air dalam jumlah yang cukup merupakan hal penting bagi suatu kota. Maka dengan sendirinya kebutuhan masyarakat terhadap air bersih dari PDAM Tirta Taman Kota Bontang setiap tahunnya mungkin saja meningkat. Pelayanan penyediaan air bersih secara nasional masih jauh dari mencukupi dan dapat dikatakan relatif kecil yakni $16.08 \%$ (Widayat, 2005).

Kenyataannya salah satu layanan PDAM Tirta Taman Kota Bontang yaitu Saleba Kelurahan Bontang Baru terdapat beberapa masalah dalam penyediaan air bersih di wilayah tersebut. Permasalahan yang timbul yakni keluhan konsumen tentang kualitas air dan ketidakmerataan debit air yang mengalir ke rumah pelanggan. Kualitas pemenuhan air bersih pada pelayanan PDAM Kota Bontang terbilang baik hanya saja masih ada endapan besi dan mangan hasil oksidasi air terhadap udara bebas (Muchtar 2015).

Pada kondisi seperti ini air yang diperoleh pelanggan masih bersifat keruh dan membawa endapan. Hal ini disebabkan air yang terbawa oleh PDAM mengandung Fe (besi) dan Mn (mangan) yang teroksida (Said, 2005). Adanya kandungan Fe dan Mn dalam air menyebabkan warna air tersebut berubah menjadi kuning kecokelatan setelah beberapa saat kontak dengan udara (Wong, 1984). Disamping dapat mengganggu kesehatan juga menimbulkan bau yang kurang enak serta menyebabkan warna kuning pada dinding bak penampungan serta bercak-bercak kuning pada pakaian.

Pada kondisi ini masyarakat harus melakukan ektra kegiatan dalam pemenuhan air dengan cara menampung pada tandon-tandon air. Setelah beberapa lama tan- don ini akan mengendapkan endapan tersebut dalam tandon. Sehingga perlu dilakukan penfilteran endapan tersebut (Alamsyah 2006). Paling mudah membuat saringan air yang terintegrasi dengan memanfaatkan karbon aktif (Muliawan and Amalinda 2016) atau membuat filter bertingkat dengan penambahan sterilizer (Muliawan and Ilmianih 2016). Pada penyaringan lempung juga dapat dilakukan pengfilteran besi dan mangan dengan memanfaatkan solenoida sebagai magnet yang dilengkapi filter berpori (Zain and Muliawan 2016).

Perlu diperhatikan, bahwa air bersih yang dihasilkan dari proses penyaringan air secara sederhana tersebut tidak dapat menghilangkan sepenuhnya garam yang terlarut di dalam air. Pemisahan zat padat dari campuran padat cair dilakukan dengan bantuan medium berpori yang disebut medium penyaring. Suspensi padat cair dipaksa melewati medium penyaring .Zat padat akan tertahan medium penyaring sedangkan cairan dapat melewatinya yang biasa disebut filtrat. Dalam beberapa penyaringan, padatan-saring yang terbentuk merupakan medium penyaring yang baik. Sehingga diperlukan penyaring dengan pori yang sangat kecil sehingga bisa menghambat besi dan mangan sebagai padatan.

Metode filter air yang akan kita gunakan adalah dengan penambahan filter berpori dengan ukuran 0,5 mikron dan 0,3 mikron serta karbon aktif. Karbon Aktif digunakan untuk menjernihkan air, pemurnian gas, industri minuman, farmasi, katalisator, dan berbagai macam penggunaan lain (Kirisits et al. 2001). Untuk mengurangi kesadahan (Hardness) pada air dapat digunakan filtrasi (penyaringan) dengan media karbon aktif yang memiliki sifat kimia dan fisika, di antaranya mampu menyerap zat organik maupun anorganik, dapat berlaku sebagai penukar kation, dan sebagai katalis untuk berbagai reaksi.

Diperlukan penelitian khusus untuk dapat mengetahui kandungan dan jumlah endapan dalam air. Oleh karena itu akan dilakukan penelitian pengunaan filter air dan uji laboratorium dalam penelitian ini. Diharapkan juga penelitian ini dapat mengatasi masalah endapan air dan menjernihkan air. 


\section{BAHAN DAN METODE}

Penelitian dilakukan pada daerah Saleba Bontang Baru yang berada letak dan posisinya dekat dari valpe pipa 6" dengan tekanan yang dapat mengangkat air hinggga naik ke tandon 2,5 meter. Pada kondisi ini instalasi pemipaan dilakukan tanpa mengunanan pompa hisap. Perancangan alat seperti yang titunjukan pada gambar 2

Bahan yang dibutuhkan dalam penelitian ini yakni

1. Catride sebanyak 3 buah

2. Filter air $0,5 \mu$ sebanyak 1 buah

3. Filter air $0,3 \mu$ sebanyak 1 buah

4. Filter air karbon aktif sebanyak 1

buah

5. Pipa paralon $1 / 2 "$

6. Sambungan dan perekat

Pelaksanaan penelitian dilakukan dengan menjalankan instruksi sebagai berikut:

Periksalah keadaan air keluaran PDAM pada instalasi rumah, jika air yang keluar diperkirakan banyak dengan tekanan berlebih, penelitian dapat dilakukan. teran PDAM

Mencatat pembacaan awal pada me-

Mencatat debit keluaran air

Susunan filter difariasikan yakni 0,5 $0,3 \mu \mathrm{m}$ dan karbon aktif

Mengambil hasil saringan filter berupa air dari filter $0,50,3 \mu \mathrm{m}$ dan karbon aktif untuk dilakukan pengujian kadar baku mutu

Pengujian baku mutu dilakukan dengan memperoleh hasil kadar kekeruhan, besi dan mangan

Pengujian kekeruhan dengan menentukan NTU, pengujian kadar besi dengan metode SNI 19-1127-1989 dan pengujian kadar mangan dengan metode SNI 19-11331989

\section{HASIL}

Pada penelitian ini telah dilakukan dengan melakukan penimbangan hasil keluaran filter terhadap bahan uji coba dengan mengambil sampel saringan yaitu filter $0,5 \mu, 0,3 \mu$ dan arang aktif.

Setelah pengaliran air selama 4 hari diperoleh hasil penimbangan dan selama 7 hari diperoleh hasil pengukuran pengunaan filter seperti yang ditunjukan pada tabel 1 (lampiran) akan terlihat perubahan bentuk fisik dari filter setelah pemakaian selama 4 hari seperti yang ditunjukan pada gambar 3.

Pada tabel 1 (lampiran) menunjukan sejumlah endapan yang terdapat pada saringan filter. Pada pengukuran kandungan hasil keluaran filter diperoleh data dari UPTD Laboratorium Kesehatan Kota Bontang menunjukan hasil yang ditunjukan pada tabel 2, 3 dan 4 .

\section{PEMBAHASAN}

Pada penelitian ini telah dilakukan dengan melakukan penimbangan hasil keluaran filter terhadap bahan uji coba dengan mengambil sampel saringan yaitu filter $0,5 \mu, 0,3 \mu$ dan arang aktif. Bahan uji coba ditunjukan pada gambar 4 (lampiran).

Pengambilan data telah dilakukan pada aliran air PDAM yang melewati rumah tangga yang diprediksi sangat kencang. Penelitian ini menggunakan 3 buah filter yang telah diuji coba kemampuanya. Pengujian filter dengan 0,5 mikron, 0,3 mikron dan karbon akktif. Pada tabel 2, 3 dan 4 menunjukan hasil laboratorium kandungan air PDAM yang telah melewati filter. Air ini akan masuk ke dalam filter dan terlihat bahwa kandungan besi dan mangan sangat besar dibawa oleh aliran. Hal ini sangat wajar dikarenakan air yang telah melalui proses penjernihan akan lambat laun mengalami pristiwa kimia yaitu oksidasi. Peristiwa oksidasi mengakibatkan besi dan mangan akan ber rekasi dengan oksigen menghasilkan endapan besi dan mangan.

Pada gambar 5, 6 dan 7 (lampiran) yang bernomor 1 diberikan tanpa filter yakni air langsung dari PDAM; yang bernomor 2 diberikan filter 0,5 mikron; yang bernomor 3 diberikan filter 0,3 mikron dan yang terakhir bernomor 4 diberikan filter karbon aktif. Pada saat air langsung diambil dari PDAM diperoleh kandungan besi 1,606 $\mathrm{mg} / \mathrm{l}$, mangan 0,157 mg/l dengan kekeruhan 91 NTU. Dengan dialirkan air ini pada filter 0,5 mikron diperoleh penurunan tingkat kandungan besi $1,101 \mathrm{mg} / \mathrm{l}$, mangan $0,141 \mathrm{mg} / \mathrm{l}$ dengan kekeruhan 74 NTU. Ditambah lagi dengan penyaringan 0,3 mikron diperoleh penurunan tingkat kandungan besi 0,309 $\mathrm{mg} / \mathrm{l}$, mangan 0,083 $\mathrm{mg} / \mathrm{l}$ dengan kekeruhan 42,49 NTU. Pada filter terakhir dengan penggunaan karbon aktif 
diperoleh penurunan tingkat kandungan besi $0,066 \mathrm{mg} / \mathrm{l}$, mangan $0,069 \mathrm{mg} / \mathrm{l}$ dengan kekeruhan 2,07 NTU.

Pada gambar 5, 6 dan 7 menunjukan kinerja penggunaan filter sebagai saringan yang mampu mengfilter besi, mangan dan kekeruhan pada air PDAM. Hasil yang diperoleh dari saringan akan menjadi bersih. Hasil keluaran dari filter ini menunjukan kemampuan filter untuk menyaring. Kedua endapan ini terfilter baik di saringan baik yang $0,5 \mu \mathrm{m}$ dan sebagian lolos ke filter $0,3 \mu \mathrm{m}$. jika berlangsung secara terus menerus maka akan mengakibatkan penimbunan endapan pada filter. Air akan semakin sukar untuk mengalir akibat endapan itu. Pada gambar 8 (lampiran) menunjukan jumlah massa benda filter yang digunakan selama kurun waktu 7 hari penggunaan filter. Saringan tersebut kemudian dilakukan penimbangan dengan cara menimbang dengan timbangan digital. Penggunaan timbangan digital pada penelitian ini dimaksudkan untuk memberikan nilai hasil yang akurat terhadap massa kotoran yang terendapkan oleh filter. Instalasi filter dilakukan dengan penyusunan bertahap terhadap filter seperti ditunjukan pada gambar 9 (lampiran) (Muliawan and Amalinda 2016).

Dari pemakaian selama 4 hari diperoleh perbedaan kondisi filter yang sangat berbeda dengan filter baru. Selama 4 hari terjadi pengfilteran air PDAM menjadi air bersih sehingga lebih bersih dan endapan air dapat ketahan. Pada gambar 8 (lampiran) terlihat bahwa endapan yang dibawa oleh air masuk ke saluran perumahan masih banyak mengandung kotoran. Sehingga sangat tepat dilakukan pengfilteran terhadap air PDAM. Dalam 4 hari setelah pemakain filter ternyata terdapat endapan yang diakibatkan oleh unsur logam yang telah mengalami oksidasi. Hal ini akan dibandingkan pula dengan hasil penggunaan filter selama 7 hari. Pada hari ke 4 diperoleh perubahan massa timbangan filter 0,5 mikron sejumlah $25 \mathrm{gr}$ dan filter 0,3 mikron sejumlah 4 gr. Sedangkan pada hari ke 7 diperoleh perubahan massa timbangan filter 0,5 mikron sejumlah 53 gr dan filter 0,3 mikron sejumlah 8 gr. Sedangkan pada karbon aktif tidak terjadi perubahan massa selama proses penfilteran. Endapan logam yang berada pada filter ini berwarna coklat sehingga sangat mengganggu distribusi air ke penampungan, endapan ini dapat menahan laju aliran sehingga distribusi air ke penampungan sulit terjadi.

\section{KESIMPULAN DAN SARAN}

Air yang mengalir dalam distribusi PDAM akan mengalami oksidasi. Oksidasi ini sering terjadi pada besi dan mangan serta terlihat kekeruhan pada distribusinya. Pada saat air langsung diambil dari PDAM diperoleh kandungan besi 1,606 mg/l, mangan 0,157 $\mathrm{mg} / \mathrm{l}$ dengan kekeruhan 91 NTU. Dengan dialirkan air ini pada filter 0,5 mikron diperoleh penurunan tingkat kandungan besi $1,101 \mathrm{mg} /$ l, mangan 0,141 mg/l dengan kekeruhan 74 NTU. Ditambah lagi dengan penyaringan 0,3 mikron diperoleh penurunan tingkat kandungan besi $0,309 \mathrm{mg} / \mathrm{l}$, mangan $0,083 \mathrm{mg} / \mathrm{l}$ dengan kekeruhan 42,49 NTU. Pada filter terakhir dengan penggunaan karbon aktif diperoleh penurunan tingkat kandungan besi 0,066 $\mathrm{mg} / \mathrm{l}$, mangan 0,069 $\mathrm{mg} / \mathrm{l}$ dengan kekeruhan 2,07 NTU. Pada hari ke 4 diperoleh perubahan massa timbangan filter 0,5 mikron sejumlah 25 gr dan filter 0,3 mikron sejumlah 4 gr. Sedangkan pada hari ke 7 diperoleh perubahan massa timbangan filter 0,5 mikron sejumlah 53 gr dan filter 0,3 mikron sejumlah 8 gr. Sedangkan pada karbon aktif tidak terjadi perubahan massa selama proses penfilteran. Dari hasil ini menunjukan bahwa penggunaan filter berpori 0,5 mikron, 0,3 mikron dan karbon aktif sangat baik untuk aliran air PDAM yang kurang bersih.

\section{DAFTAR PUSTAKA}

Alamsyah, Sujana. 2006. Merakit Sendiri Alat Penjernihan Air Untuk Rumah Tangga. Kawan Pustaka.

Kirisits, M. J. et al. 2001. "Water Quality Factors Affecting Bromate Reduction in Biologically Active Carbon Filters." Water Research 35(4): 891-900.

Muchtar, Ilham. 2015. Universitas Trunajaya "Pembuatan Filter Air Yang Dapat Mengubah Air PDAM Menjadi Air Siap Minum."

Muliawan, Arief, and Finta Amalinda. 2016. "Pengaruh Jumlah Karbon Aktif Pada Filter Air Terhadap Tekanan Keluaran Hasil Filter." Jurnal Promotif 5(2): 11220. 
Muliawan, Arief, and Rizki Ilmianih. 2016. "Metoda Pengurangan Zat Besi Dan Mangan Menggunakan Filter Bertingkat Dengan Penambahan UV Sterilizer Skala Rumah Tangga." Jurnal Ilmiah Giga 19(1): 1-8.

Said, Nusa Idaman. 2005. "Metoda Penghilangan Zat Besi Dan Mangan Di Dalam Penyediaan Air Minum Domestik." Jurnal Air Indonesia 1(3).

Widayat, Wahyu. 2005. "Teknologi Pengolahan Air Siap Minum Untuk Daerah Padat Penduduk." Jurnal Air Indonesia $1(2)$.

Wong, J.M. 1984. "Chlorination-Fitration for Iron and Maganese Removal." Journal AWWA 76(1).

Zain, Abdul, and Arief Muliawan. 2016. "Studi Penurunan Kadar Logam Besi ( $\mathrm{Fe}$ ) Dan Logam Mangan ( $\mathrm{Mn}$ ) Pada Lempung Terhadap Perubahan Arus Listrik Dalam Solenoida." Journal INTEK 3(2): 72-76. 
Tabel 1. Hasil Pengukuran Massa Pemakaian Filter

\begin{tabular}{|c|c|c|c|}
\hline $\begin{array}{c}\text { Pengukuran } \\
\text { Hari (ke) } \\
\end{array}$ & $\begin{array}{c}\text { Filter } 0,5 \mu \mathrm{m} \\
(\mathrm{gr})\end{array}$ & $\begin{array}{c}\text { Filter } 0,3 \mu \mathrm{m} \\
(\mathrm{gr})\end{array}$ & $\begin{array}{c}\text { Arang aktif } \\
\text { (gr) }\end{array}$ \\
\hline 0 & 134 & 138 & 400 \\
\hline 4 & 159 & 142 & 400 \\
\hline 7 & 187 & 146 & 400 \\
\hline
\end{tabular}

Sumber: Data Primer 2017

Tabel 2. Parameter Kekeruhan

\begin{tabular}{lccc}
\hline \multicolumn{1}{c}{ Filter } & Satuan & Baku Mutu & Hasil \\
\hline Non & NTU & 25 & 91 \\
0,5 & NTU & 25 & 74 \\
0,3 & NTU & 25 & 42.49 \\
Karbon aktif & NTU & 25 & 2,07 \\
\hline
\end{tabular}

Sumber: Lab Kesda Bontang 2017

Tabel 3. Parameter Besi

\begin{tabular}{lccc}
\hline \multicolumn{1}{c}{ Filter } & Satuan & Baku Mutu & Hasil \\
\hline Non & $\mathrm{mg} / \mathrm{L}$ & 1,0 & 1,606 \\
0,5 & $\mathrm{mg} / \mathrm{L}$ & 1,0 & 1,101 \\
0,3 & $\mathrm{mg} / \mathrm{L}$ & 1,0 & 0,309 \\
Karbon aktif & $\mathrm{mg} / \mathrm{L}$ & 1,0 & 0.066 \\
\hline
\end{tabular}

Sumber: Lab Kesda Bontang 2017

Tabel 4. Parameter Mangan

\begin{tabular}{lccc}
\hline \multicolumn{1}{c}{ Filter } & Satuan & Baku Mutu & Hasil \\
\hline Non & $\mathrm{mg} / \mathrm{L}$ & 0,5 & 0,157 \\
0,5 & $\mathrm{mg} / \mathrm{L}$ & 0,5 & 0,141 \\
0,3 & $\mathrm{mg} / \mathrm{L}$ & 0,5 & 0,083 \\
Karbon aktif & $\mathrm{mg} / \mathrm{L}$ & 0,5 & 0,069 \\
\hline
\end{tabular}

Sumber: Lab Kesda Bontang 2017 


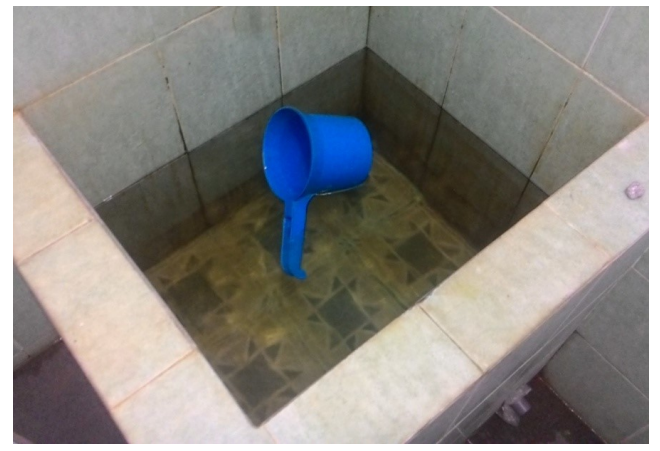

Gambar 1. Bak Penampungan air

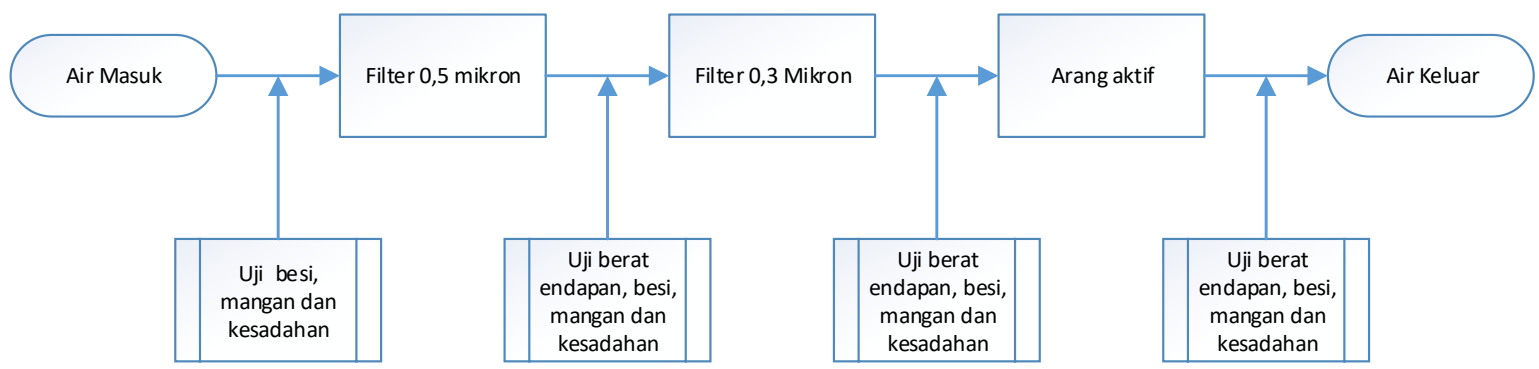

Gambar 2. Skema Penelitian
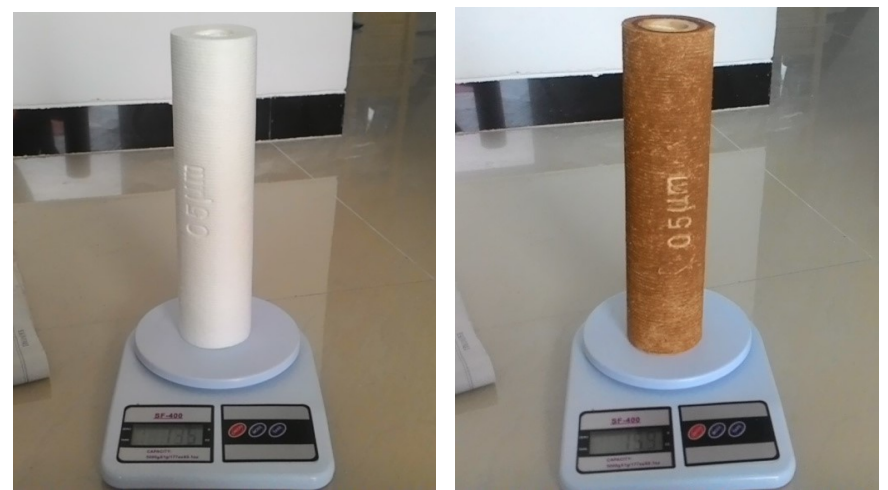

Gambar 3. Penimbangan Filter Setelah Pengunaan

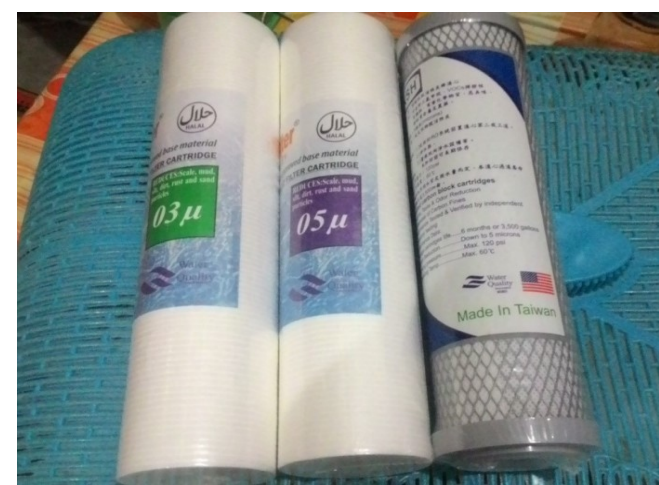

Gambar 4. Saringan $0,5 \mu, 0,3 \mu$ dan Arang Aktif 


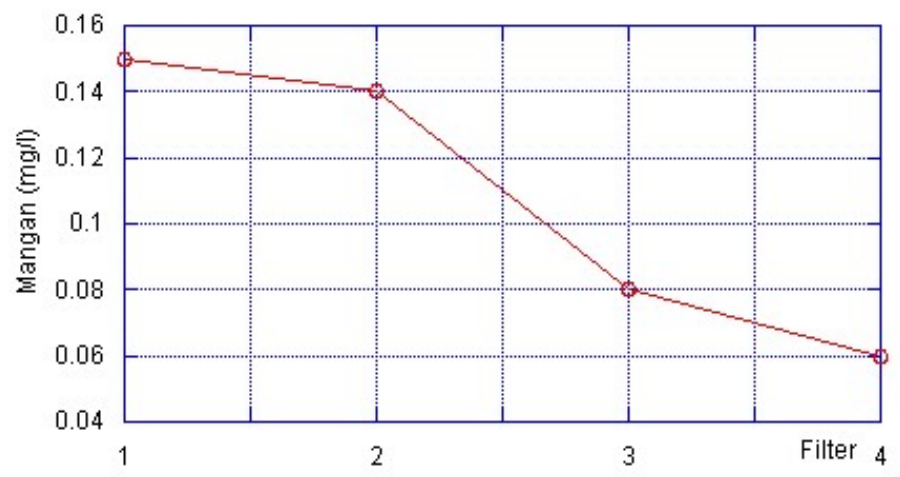

Gambar 5. Perubahan Jumlah Mangan Dalam Air Melewati Filter

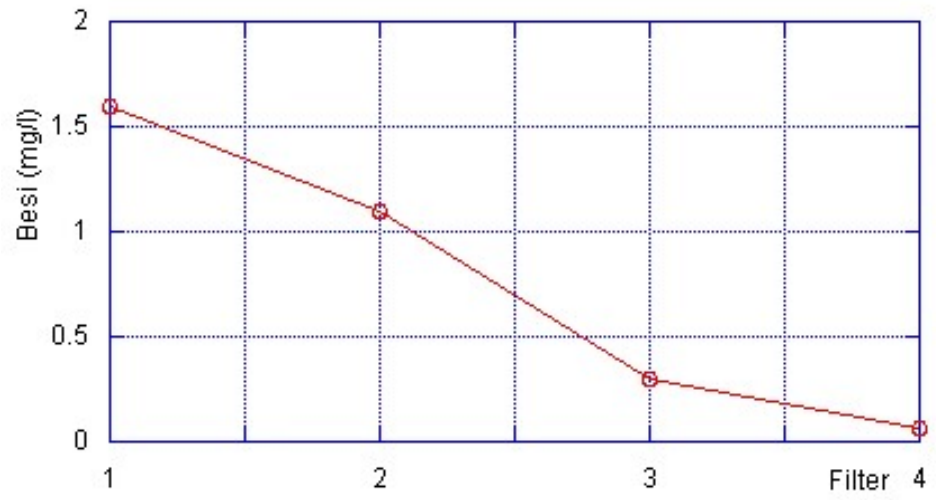

Gambar 6. Perubahan Jumlah Besi Dalam Air Melewati Filter

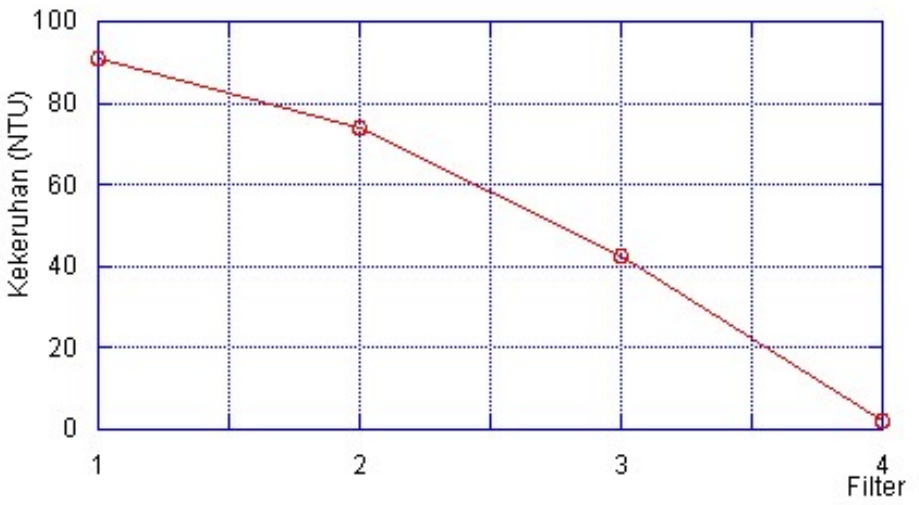

Gambar 7. Perubahan Kekeruhan Dalam Air Melewati Filter

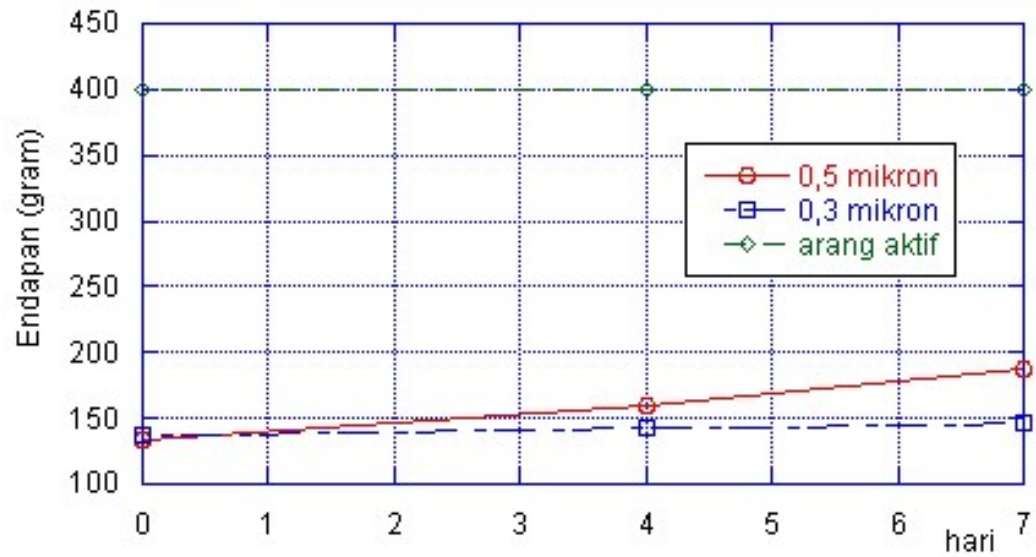

Gambar 8 Perubahan Massa Endapan Dan Filter Dalam Selang Waktu 7 Hari 


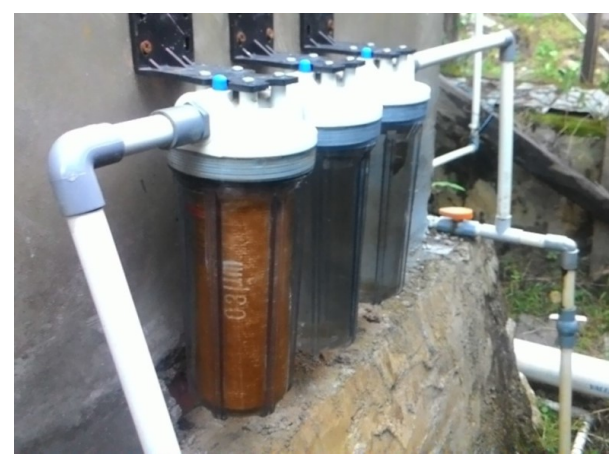

Gambar 9 Susunan Filter Diserikan

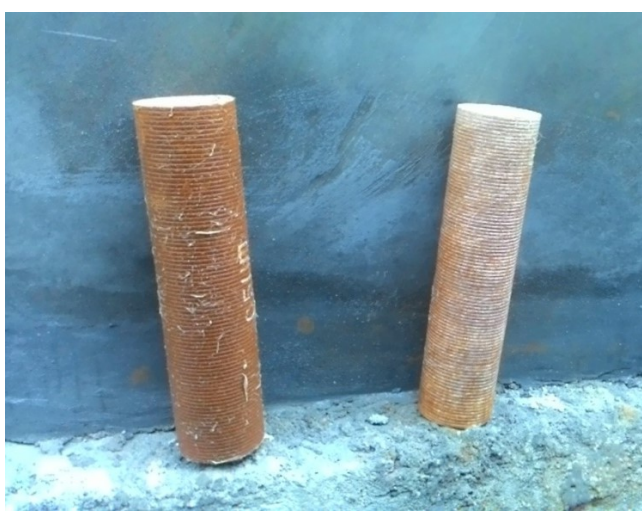

Gambar 10. Perubahan Filter Air Setelah 4 Hari Pemakaian 